\title{
Design and Implementation of STATCOM Controller for a Three Phase SEIG Feeding Single Phase Loads
}

\author{
Addanki Gopinadh ${ }^{1}$, Pasupulety Ankamarao ${ }^{2}$ \\ P.G. SCHOLAR, EEE, Amrita Sai Institute of Science and Technology, Paritala, India ${ }^{1}$ \\ M.Tech, Asst .professor, EEE, Amrita Sai Institute of Science and Technology, Paritala, India ${ }^{2}$
}

\begin{abstract}
The main aim of the project is to compensate the unbalanced currents caused by single-phase loads that are connected across any two terminals of the three-phase SEIG by using STATCOM with D-Q theory technique. This project presents single-phase power generation using a three-phase self-excited induction generator (SEIG) working in conjunction with a three-phase static synchronous compensator (STATCOM). Due to the specific advantages of the squirrel-cage induction machine over the conventional synchronous machine, SEIGs are being employed in remote and isolated power generating systems as mechanical energy conversion devices. When an SEIG is driven by prime movers such as biomass, biogas, and biodiesel engines, the frequency of the generated voltage is almost constant from no load to full load. But, poor voltage regulation has been the major drawback of an SEIG in its applications. To control the terminal voltage by using one of the controlling equipment like active switches which use the combination of a fixed capacitor and thyristor-controlled inductor known as static var compensator (SVC), the disadvantage of SVC is it would generate low-order harmonic currents caused by the switching of line currents and they also involve large size and heavy weight of passive elements. The performance of the SEIG-STATCOM system is evaluated for both linear and nonlinear single-phase loads. Furthermore, the performance of the SEIG at different terminal voltages is observed and the terminal voltage corresponding to the maximum power output is identified and also observes the source current and load current by using SIMULINK/MATLAB software. In this project, an alternative method of feeding singlephase loads using a three-phase SEIG without de-rating the machine is proposed. The benefit of integrating a STATCOM in an SEIG based Standalone power generation feeding single-phase loads is threefold first, generator currents balancing; second, voltage regulation; and third, mitigates the harmonics injected by nonlinear loads.
\end{abstract}

Keywords: Self-excited induction generator (SEIG), single-phase Synchronous D-Q frame theory, static synchronous compensator (STATCOM).

\section{INTRODUCTION}

An externally driven squirrel-cage induction machine with Its stator terminals connected to a reactive power source (Capacitance) is popularly known as a self-excited induction generator (SEIG).Due to the specific advantages of the squirrel-cage induction machine over the conventional synchronous machine such as low cost, brush-less construction, ruggedness, cheap, and inherent short-circuit protection, SEIGs are being employed in remote and isolated power generating systems as mechanical energy conversion devices. When an SEIG is driven by prime movers such as biomass, biogas, and biodiesel engines, the frequency of the generated voltage is almost constant from no load to full load. But, poor voltage regulation has been the major drawback of an SEIG in its applications. Hence, the terminal voltage of an SEIG needs to be regulated during load disturbances. Several voltage regulating schemes have been reported for SEIG-based autonomous power generation systems. have employed passive elements for voltage regulation .Have proposed a voltage compensation method for a three-phase SEIG using the long-shunt method. Have used the shortshunt compensation method for a three-phase SEIG. The methods employing only passive elements are not capable of regulating the terminal voltage when the nature of the load changes. Therefore, some attempts have been made to maintain a constant terminal voltage using active switches which use the combination of a fixed capacitor and thyristor-controlled inductor known as static var compensator (SVC).The SVC-based voltage regulating methods would generate low-order harmonic currents caused by the switching of line currents and they also involve large size and heavy weight of passive elements. With the development of fast acting self commutating switches, pulse width modulated (PWM) voltage source inverter (VSI)-based static reactive power compensators (STATCOMs) have been evolved. These STATCOM based voltage regulators exhibit better dynamic performance and their voltage regulation capability would not be affected by nature of the load.

Since many of the isolated power generating systems feed single-phase loads, single-phase induction generators can also be used. A single-phase induction machine with a proper excitation capacitance can be used as a generator.

In general, single-phase machines are limited to relatively small power outputs. For larger power ratings above $5 \mathrm{~kW}$, three-phase machines are more efficient, cheaper, and readily available. Hence, a three phase SEIG can be used in single-phase applications. A number of attempts have been made to operate a three-phase SEIG in a single-phase 
mode. In all these methods, the SEIG cannot be loaded up to its rated power, requires de-rating of the machine. Moreover, the SEIG currents are not balanced and unequal voltages across the generator windings are the major drawbacks of the aforementioned single-phasing methods of a three-phase SEIG .In this paper, an alternative method of feeding single-phase Loads using a three-phase SEIG without de-rating the machine is proposed. In this method, a three-phase SEIG works in conjunction with a threephase STATCOM and the single-phase loads are connected across two of the three terminals of the SEIG. The benefit of integrating a STATCOM in an SEIG based standalone power generation feeding single-phase loads is threefold first, generator currents balancing; second, voltage regulation; and third, mitigates the harmonics injected by nonlinear loads. The STATCOM injects compensating currents to make the SEIG currents balanced and regulates the system voltage as well. Moreover, this method offers balanced voltages across the generator windings and ensures the sinusoidal winding currents while feeding nonlinear loads.

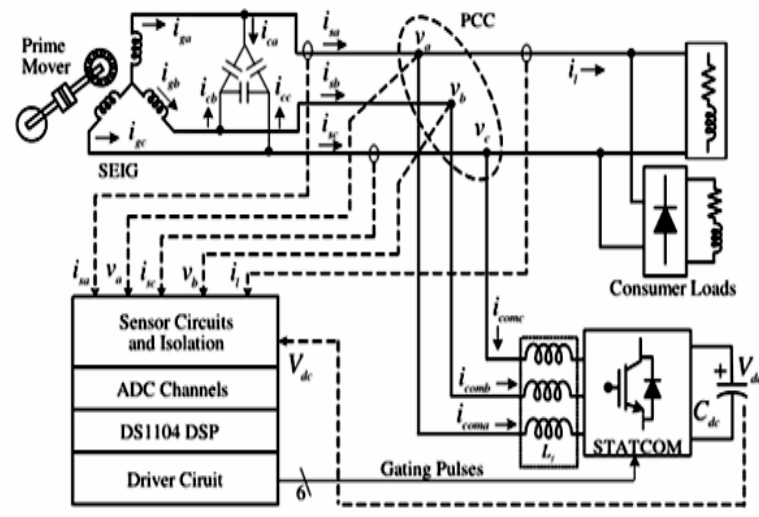

Fig. 1. Schematic diagram of the SEIG-STATCOM system feeding single-phase loads.

Although a number of publications have been reported on the STATCOM-based controller for SEIG systems, all the functions of a STATCOM such as current balancing, voltage regulation, and harmonic currents suppression are not experimentally demonstrated. The simulation of the PI (Proportional plus Integral) controller-based control scheme for voltage profile improvement using the STATCOM. The major drawback of the PI controllerbased control scheme is its instability under transients as it does not consider load currents while estimating the amplitudes of active and reactive components of reference source currents. The outputs of the STATCOM's dc-bus voltage PI controller and the system ac voltage PI controller are directly considered as the amplitudes of active and reactive components of reference source currents, respectively. Therefore, the control algorithm presented in requires adjustment of PI controller gains under transients, otherwise it causes severe peak overshoot and undershoot of the dc-bus voltage of the STATCOM. The SEIG voltage control employing a battery-assisted STATCOM using conventional three-phase D-Q frame theory-based control. The transient response of this scheme is found to be sluggish as the system is gradually reaching steady state after disturbance. Moreover, the additional important features of the STATCOM such as current balancing and current harmonics suppression have not been explored. TO control algorithm for the STATCOM in frequency perturbed systems to avoid loss of synchronization under random varying loads. Its performance is also demonstrated only for three-phase balanced linear loads. Therefore, this paper proposes a single-phase synchronous D-Q frame based control algorithm for a three-phase STATCOM system, which is capable of producing balanced source currents even under heavy unbalance currents and voltages caused by singlephase loads. Unlike the control algorithm.

The proposed control takes the load current into account, the average active and reactive power components of load current are added/subtracted to the output of the dc-bus voltage PI controller and ac voltage PI controller, respectively. Therefore, in the proposed control algorithm, adjustment of PI controller gains is not required under transients. Since the system under investigation is an isolated power generating system feeding local loads, the generated voltages are presumed to be balanced. The proposed method of feeding single-phase loads from a three-phase SEIG is tested experimentally and the benefits of incorporating a STATCOM to balance SEIG currents and system voltage regulation are demonstrated with experimental results. Moreover, the performance of the SEIG at different terminal voltages is investigated and the terminal voltage corresponding to the maximum power output is identified.

\section{II.SYSTEM CONFIGURATION ANDPRINCIPL OF OPERATION}

Fig. 1 shows the schematic diagram of the STATCOM compensated three-phase SEIG feeding single- phase loads. The system consists of an SEIG driven by renewable energy-based prime mover. The single-phase consumer loads are connected across " $a$ " and " $c$ " phases of the SEIG. A two-level, three-leg insulated-gate bipolar transistor (IGBT)-based VSI with a self sustaining dc-bus capacitor is used as a STATCOM. The STATCOM is connected at point of common coupling (PCC) through filter inductors as shown in Fig. 1. The STATCOM regulates the system voltage by maintaining equilibrium among the reactive power circulations within the system. Moreover, the STATCOM suppresses harmonics injected by nonlinear loads and provides load balancing while feeding single-phase loads.

The unbalanced load currents in a three-phase system can be divided into two sets of balanced currents known as positive sequence components and negative sequence components

In order to achieve balanced source currents, the source should be free from the negative sequence components of load currents. Therefore, when the STATCOM is connected across PCC, it supplies the negative sequence currents needed by the unbalanced load or it draws another set of negative sequence currents which are exactly 180 . out of phase to those drawn by unbalanced load so as to nullify the effect of negative sequence currents of unbalanced loads. 


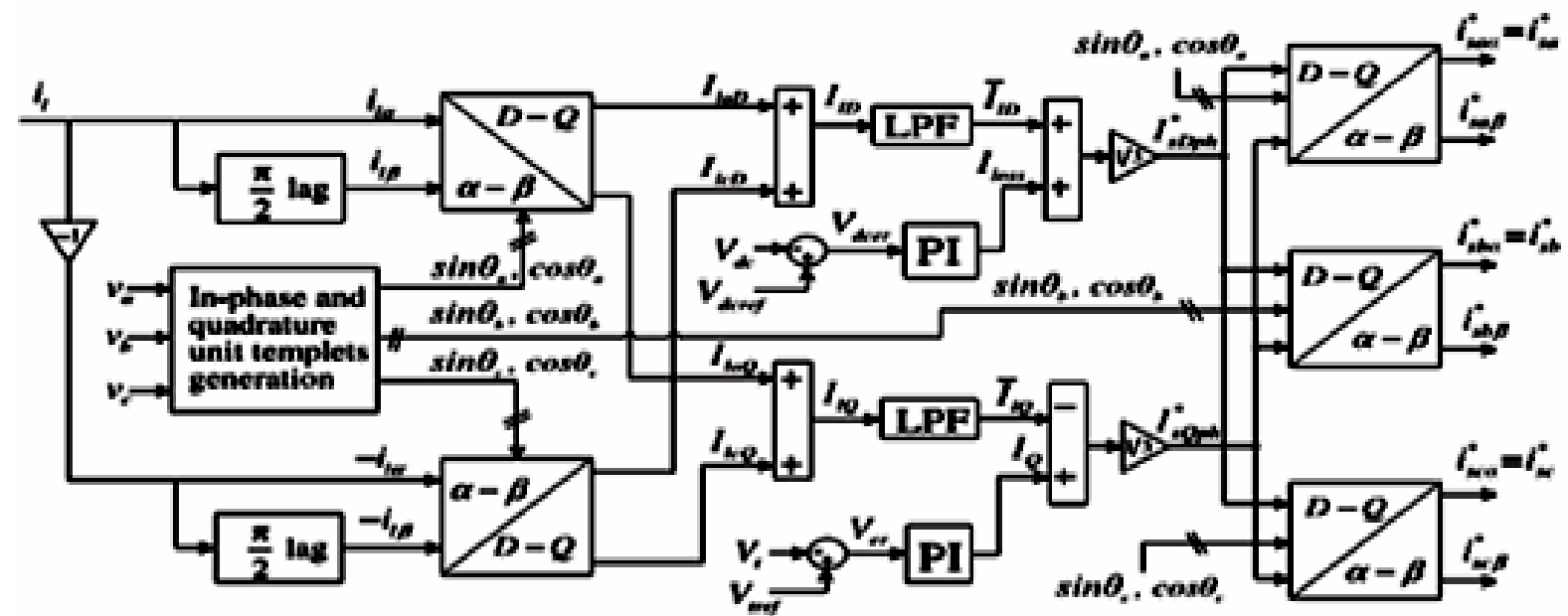

Figure.2: Block diagram of single-phase synchronous D-Q theory control algorithm for STATCOM

III. CONTROL ALGORITHM OF THE STATCOM

Fig. 2 shows the block diagram of the proposed singlephase synchronous D-Q frame theory-based control algorithm for the three-phase STATCOM. The reference source currents $(i * s a, i * s b, i * s c)$ for regulating the terminal voltage and current balancing are computed using a singlephase synchronous D-Q frame theory applied to the threephase SEIG system.

\section{A. Single-Phase Synchronous Rotating D-Q Frame Theory}

It is simple to design a controller for a three-phase system in synchronously rotating D-Q frame because all the timevarying signals of the system become dc quantities and time-invariant. In case of a three-phase system, initially, the three-phase voltages or currents (in abc frame) are transformed to a stationary frame $(\alpha-\beta)$ and then to synchronously rotating D-Q frame. Similarly, to transform an arbitrary signal " $\mathrm{x}(\mathrm{t})$ ") of a single-phase system into a synchronously rotating D-Q frame, initially that variable is transformed into a stationary $\alpha-\beta$ frame using the singlephase $\mathrm{p}-\mathrm{q}$ theory and then to a synchronously rotating D-Q frame.

Therefore, to transform a signal into a stationary $\alpha-\beta$ frame, at least two phases are needed. Hence, a pseudo second phase for the arbitrary signal $\mathrm{x}(\mathrm{t})$ is created by giving 90 . lag to the original signal. The original signal represents the component of $\alpha$-axis and 90 lag signal is the $\beta$-axis component of stationary reference frame.

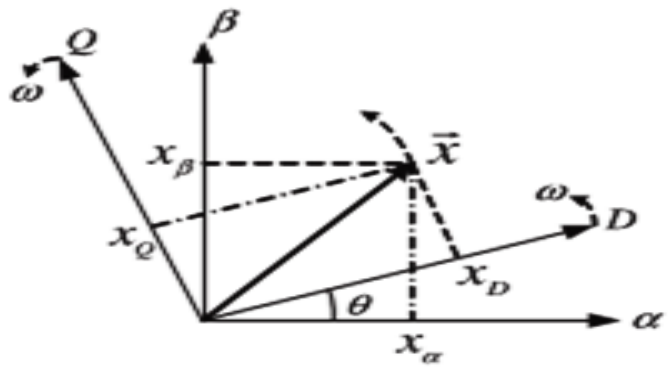

Fig.3. Stationary $\alpha-\beta$ frame and synchronously rotating D-Q frame representation of vector $\mathrm{x}(\mathrm{t})$.
Therefore, an arbitrary periodic signal $x(t)$ with a time period of " $T$ " can be represented in a stationary $\alpha-\beta$ frame as

$$
\mathrm{x}_{\alpha}(\mathrm{t})=\mathrm{x}(\mathrm{t}) ; \mathrm{x}_{\beta}(\mathrm{t})=\mathrm{x}\left(\mathrm{t}-\frac{\mathrm{T}}{4}\right)
$$

For a single-phase system, the concept of the stationary $\alpha-\beta$ frame and synchronously rotating D-Q frames relative to an arbitrary periodic signal $x(t)$ is illustrated in Fig. 3. The signal $x(t)$ is represented as vector $\mathrm{x}(\mathrm{t})$ and the vector $x$ can be decomposed into two components $x_{\alpha}$ and $x_{\beta}$. As the vector $x$ rotates around the center, its component $x_{\alpha}$ and $x_{\beta}$ which are the projections on the $\alpha-\beta$ axes vary in time accordingly. Now, considering that there are synchronously rotating $\mathrm{D}-\mathrm{Q}$ coordinates that rotate with the same angular frequency and direction as vector $x$, then the position of vector $x$ with respect to its components $x_{D}$ and $x_{Q}$ is same regardless of time. Therefore, it is clear that the $x_{D}$ and $x_{Q}$ do not vary with time and only depend on the magnitude of vector $x$ and its relative phase with respect to the D-Q rotating frame. The angle $\theta$ is the rotating angle of the D-Q frame and it is defined as

$$
\theta=\int_{0}^{\mathrm{t}} \omega \mathrm{dt}
$$

where $\omega$ is the angular frequency of the arbitrary variable $x$.

The relationship between stationary and synchronous rotating frames can be derived. The components of the arbitrary single-phase variable $\mathrm{x}(\mathrm{t})$ in the stationary reference frame are transformed into the synchronously rotating D-Q frame using the transformation matrix " $\mathrm{C}$ " as

Where,

$$
\left[\begin{array}{l}
x_{D} \\
x_{Q}
\end{array}\right]=C\left[\begin{array}{l}
x_{\alpha} \\
x_{\beta}
\end{array}\right]
$$

$$
\mathrm{C}=\left[\begin{array}{cc}
\cos \theta & \sin \theta \\
-\sin \theta & \cos \theta
\end{array}\right]
$$

B. Reference Source Currents Estimation Using SinglePhase Synchronous Rotating D-Q Frame Theory:

The main objective of employing a three-phase STATCOM in a three-phase SEIG-based standalone power generating system feeding single-phase consumer loads is to balance the generator currents so that the 
generator can be loaded to its full capacity without rerating. The control structure of the STATCOM employs an ac voltage PI controller to regulate the system voltage and a dc bus voltage PI controller to maintain the dc bus capacitor voltage constant and greater than the peak value of the line voltage of PCC for successful operation of the STATCOM. The PCC voltages $\left(\mathrm{v}_{\mathrm{a}}, \mathrm{v}_{\mathrm{b}}, \mathrm{v}_{\mathrm{c}}\right)$, source currents $\left(i_{\mathrm{sa}}, i_{\mathrm{sb}}, i_{\mathrm{sc}}\right)$, load current $\left(\mathrm{i}_{\mathrm{l}}\right)$, and dc bus voltage $\left(\mathrm{V}_{\mathrm{dc}}\right)$ are sensed and used as feedback signals. Considering PCC voltages as balanced and sinusoidal, the amplitude of the PCC voltage (or system voltage) is estimated as

$$
\mathrm{V}_{\mathrm{t}}=\sqrt{\frac{2}{3}\left(\mathrm{v}_{\mathrm{a}}^{2}+\mathrm{v}_{\mathrm{b}}^{2}+\mathrm{v}_{\mathrm{c}}^{2}\right)}
$$

Consider one of the three phases at a time and then transform the voltages and currents of that particular phase into a Stationary $\alpha-\beta$ frame, then the PCC voltages and load current in stationary $\alpha-\beta$ frame are represented as

$$
\begin{aligned}
\mathrm{v}_{\mathrm{a} \alpha}(\mathrm{t})=\mathrm{v}_{\mathrm{a}}(\mathrm{t}) ; \mathrm{v}_{\mathrm{b} \alpha}(\mathrm{t})=\mathrm{v}_{\mathrm{b}}(\mathrm{t}) ; \mathrm{v}_{\mathrm{c} \alpha} \\
\mathrm{v}_{\mathrm{a} \beta}(\mathrm{t})=\mathrm{v}_{\mathrm{a}}\left(\mathrm{t}-\frac{\mathrm{T}}{4}\right) \\
\mathrm{v}_{\mathrm{b} \beta}(\mathrm{t})=\mathrm{v}_{\mathrm{b}}\left(\mathrm{t}-\frac{\mathrm{T}}{4}\right) \\
\mathrm{v}_{\mathrm{c} \beta}(\mathrm{t})=\mathrm{v}_{\mathrm{c}}\left(\mathrm{t}-\frac{\mathrm{T}}{4}\right) \\
\mathrm{i}_{\mathrm{l} \alpha}(\mathrm{t})=\mathrm{i}_{\mathrm{l}}(\mathrm{t}) ; \mathrm{i}_{\mathrm{l} \beta}(\mathrm{t})=\mathrm{i}_{\mathrm{l}}\left(\mathrm{t}-\frac{\mathrm{T}}{4}\right)
\end{aligned}
$$

The sinusoidal signal filters based on a second-order generalized integrator or a sinusoidal signal integrator (SSI) can be used for creating $\beta$-axis signals which are lagging the original signals. In the present investigation, a filter based on SSI is used. The SSI filters generate quadrature signals using system frequency information. Since the system frequency fluctuates under load perturbations, a PLL is used to continuously estimate the system frequency, and the estimated frequency is fed to SSI filters which makes the proposed control adaptive to frequency fluctuations, thereby avoids the loss of synchronization of the STATCOM.

Now consider a synchronously rotating D-Q frame for phase "a" which is rotating in the same direction as $v_{a}(t)$, and the projections of the load current $i_{1}(t)$ to the D-Q axes give the $\mathrm{D}$ and $\mathrm{Q}$ components of the load current. Therefore, the D-axis and Q-axis components of the load current in phase "a" are estimated as

$$
\left[\begin{array}{l}
\mathrm{I}_{\mathrm{laD}} \\
\mathrm{I}_{\mathrm{laQ}}
\end{array}\right]=\left[\begin{array}{cc}
\cos \theta_{\mathrm{a}} & \sin \theta_{\mathrm{a}} \\
-\sin \theta_{\mathrm{a}} & \cos \theta_{\mathrm{a}}
\end{array}\right]\left[\begin{array}{l}
\mathrm{I}_{\mathrm{l} \alpha} \\
\mathrm{I}_{\mathrm{l} \beta}
\end{array}\right]
$$

Where $\cos \theta_{\mathrm{a}}$ and $\sin \theta_{\mathrm{a}}$ are estimated using $\mathrm{v}_{\mathrm{a} \alpha}$ and $\mathrm{v}_{\mathrm{a} \beta}$ as follows:

$$
\left[\begin{array}{c}
\cos \theta_{\mathrm{a}} \\
\sin \theta_{\mathrm{a}}
\end{array}\right]=\frac{1}{\sqrt{\mathrm{v}_{\mathrm{a} \alpha}^{2}+\mathrm{v}_{\mathrm{a} \beta}^{2}}}\left[\begin{array}{c}
\mathrm{v}_{\mathrm{a} \alpha} \\
\mathrm{v}_{\mathrm{a} \beta}
\end{array}\right]
$$

$I_{\mathrm{laD}}$ represents the active power component of the load current as the signals belong to the same axis are multiplied and added to estimate the D-axis component, where as $\mathrm{I}_{\mathrm{laQ}}$ represents the reactive power component of the load current as the orthogonal signals are multiplied and added to derive the Q-axis component. Similarly, the D-axis and Q-axis components of the load current in phase "c" are estimated as

$$
\left[\begin{array}{l}
\mathrm{I}_{\mathrm{lcD}} \\
\mathrm{I}_{\mathrm{lcQ}}
\end{array}\right]=\left[\begin{array}{cc}
\cos \theta_{\mathrm{c}} & \sin \theta_{\mathrm{c}} \\
-\sin \theta_{\mathrm{c}} & \cos \theta_{\mathrm{c}}
\end{array}\right]\left[\begin{array}{l}
-\mathrm{I}_{\mathrm{l} \alpha} \\
-\mathrm{I}_{\mathrm{l} \beta}
\end{array}\right]
$$

The negative sign of currents in (11) indicates that the load current in phase "c" is equal to phase "a" but $180^{\circ}$ out of phase. As the single-phase load is connected across the phases "a" and "c," D-axis and Q-axis components for phase " $b$ " are not estimated. The D-axis components of the load current in phases "a" and "c" are added together to obtain an equivalent D-axis current component of total load on the SEIG as

$$
\mathrm{I}_{\mathrm{lD}}=\mathrm{I}_{\mathrm{laD}}+\mathrm{I}_{\mathrm{lcD}}
$$

Similarly, an equivalent Q-axis current component of total load on the system is estimated as

$$
\mathrm{I}_{\mathrm{lQ}}=\mathrm{I}_{\mathrm{laQ}}+\mathrm{I}_{\mathrm{lcQ}}
$$

The equivalent D-axis and Q-axis current components of total load are decomposed into two parts namely fundamental and oscillatory parts as

$$
\begin{aligned}
& \mathrm{I}_{\mathrm{lD}}=\overline{\mathrm{I}}_{\mathrm{lD}}+\tilde{\mathrm{I}}_{\mathrm{lD}} \\
& \mathrm{I}_{\mathrm{lQ}}=\overline{\mathrm{I}}_{\mathrm{lQ}}+\tilde{\mathrm{I}}_{\mathrm{lQ}}
\end{aligned}
$$

The reason for the existence of the oscillatory part is due to the nonlinear and single-phase nature of connected loads in the system. Even if the connected loads are linear in nature, the D and Q components estimated in (12) and (13) would still contain oscillatory parts due to the unbalance caused by single-phase loads. To ensure the power quality, the reference $\mathrm{D}$-axis and $\mathrm{Q}$-axis components of source currents must be free from these oscillatory components. Hence, the signals $\mathrm{I}_{\mathrm{ID}}$ and $\mathrm{I}_{\mathrm{lQ}}$ are passed through low-pass filters (LPFs) to extract the fundamental (or dc) components as shown in Fig 4.2. To maintain the dc-bus capacitor voltage of the STATCOM at a reference value, it is sensed and compared with the reference value and then obtained the voltage error is processed through a PI controller. The dc-bus voltage error of the STATCOM $\mathrm{V}_{\mathrm{dcer}}$ at $\mathrm{k}_{\mathrm{th}}$ sampling instant is expressed as

$$
\mathrm{V}_{\mathrm{dcer}}(\mathrm{k})=\mathrm{V}_{\mathrm{dcref}}(\mathrm{k})-\mathrm{V}_{\mathrm{dc}}(\mathrm{k})
$$

Where $V_{d c r e f}(k)$ and $V_{d c}(k)$ are the reference and sensed dcbus voltages of the STATCOM at kth sampling instant, respectively. In the present investigation, the dc-bus voltage reference is set to $400 \mathrm{~V}$. The output of the PI controller for maintaining a constant dc bus voltage of the STATCOM at kth sampling instant is expressed as

$$
\begin{aligned}
\mathrm{I}_{\text {loss }}(\mathrm{k})= & \mathrm{I}_{\text {loss }}(\mathrm{k}-1)+\mathrm{K}_{\mathrm{pd}}\left\{\mathrm{V}_{\mathrm{dcer}}(\mathrm{k})+\mathrm{V}_{\mathrm{dcer}}(\mathrm{k}-1)\right\}+ \\
& \mathrm{K}_{\mathrm{id}} \mathrm{V}_{\mathrm{dcer}}(\mathrm{k})
\end{aligned}
$$

Where $I_{\text {loss }}$ is the active power component of the current (or D-axis current component) that must be supplied to meet the losses in the STATCOM. $\mathrm{K}_{\mathrm{pd}}$ and $\mathrm{K}_{\mathrm{id}}$ are the proportional and integral gain constants of the dc-bus voltage PI controller, respectively. The source should supply the power loss component of the current $\left(\mathrm{I}_{\text {loss }}\right)$ along with the filtered equivalent D-axis current component of the single-phase load estimated in (14). In order to ensure balanced and sinusoidal source currents, the D-axis component of source currents after compensation must be equal for all the phases and it should not contain any ripple. Therefore, $I_{I D}$ is added to 
$\mathrm{I}_{\text {loss }}$ and distributed among all the phases equally to obtain the D-axis component of the reference source current in each phase which can be expressed as

$$
\mathrm{I}_{\mathrm{SDph}}^{*}=\frac{\mathrm{I}_{\mathrm{ld}}+\mathrm{I}_{\text {loss }}}{3}
$$

$\mathrm{I}_{\text {sDph }}^{*}$ also indicates the active power component of the current that should be supplied by the source after compensation. For regulating the system voltage (i.e., PCC voltage), the STATCOM has to inject the reactive power component of the current to meet the reactive power demands of both the load and SEIG. The amount of the reactive power component of the current to be injected by the STATCOM is estimated by an ac voltage PI controller. The amplitude of the PCC voltage computed in (5) is compared with the reference voltage. The PCC voltage error $\mathrm{V}_{\mathrm{er}(\mathrm{k})}$ at $\mathrm{kth}$ sampling instant is given as

$$
\mathrm{V}_{\mathrm{er}}(\mathrm{k})=\mathrm{V}_{\text {tref }}(\mathrm{k})-\mathrm{V}_{\mathrm{t}}(\mathrm{k})
$$

Where $V_{\text {tref }}$ is the amplitude of the reference PCC voltage and $\mathrm{V}_{\mathrm{t}(\mathrm{k})}$ is the amplitude of sensed three-phase ac voltages at the PCC terminals, at $\mathrm{k}^{\text {th }}$ instant. The reference voltage is selected to maintain the PCC line voltage at $220 \mathrm{~V}$. The output of the PI controller for maintaining the PCC voltage at the reference value in kth sampling instant is expressed as

$$
\mathrm{I}_{\mathrm{Q}}(\mathrm{k})=\mathrm{I}_{\mathrm{Q}}(\mathrm{k}-1)+\mathrm{Kpa}\{\operatorname{Ver}(\mathrm{k})+\operatorname{Ver}(\mathrm{k}-1)\}+\operatorname{KiaVer}(\mathrm{k})
$$

Where $\mathrm{K}_{\mathrm{pa}}$ and $\mathrm{K}_{\mathrm{ia}}$ are the proportional and integral gain constants of the PI controller, $\mathrm{V}_{\mathrm{er}}(\mathrm{k})$ and $\mathrm{V}_{\mathrm{er}}(\mathrm{k}-1)$ are the voltage errors at $\mathrm{k}_{\mathrm{th}}$ and $(\mathrm{k}-1)^{\text {th }}$ instants, respectively. $\mathrm{I}_{\mathrm{Q}}(\mathrm{k})$ is the equivalent $\mathrm{Q}$-axis component (or reactive power component) of the current to be supplied by the STATCOM to meet the reactive power requirements of both the load and SEIG, thereby it maintains the PCC voltage at the reference value. The per phase Q-axis component of the reference source current required to regulate the system voltage is defined as

$$
\mathrm{I}_{\mathrm{SQph}}^{*}=\frac{\overline{\mathrm{I}}_{\mathrm{Q}}+\mathrm{I}_{\mathrm{Q}}}{3}
$$

$\mathrm{I}_{\text {sQph }}^{*}$ indicates the magnitude of the reactive power component of the current that should be supplied to each phase of the source (i.e., SEIG) to achieve the reference terminal voltage. The value of $\mathrm{I}^{*}{ }_{\mathrm{sQph}}$ can be either positive or negative based on loading conditions. Using the D-axis and Q-axis components of currents derived in (18) and (21), the phase "a," $\alpha$-axis and $\beta$-axis components of the reference source current can be estimated as

$\left[\begin{array}{l}i^{*} s a \alpha \\ i^{*} s a \beta\end{array}\right]=\left[\begin{array}{cc}\cos \theta_{a} & \cos \theta \\ -\sin \theta_{a} & \cos \theta_{a}\end{array}\right]^{-1}\left[\begin{array}{l}I^{*} s D p h \\ I^{*} s Q p h\end{array}\right]$

In the above matrix, the $\alpha$-axis current represents the reference source current of actual phase "a," and the $\beta$-axis current represents the current that is at $\pi / 2$ phase lag which belongs to the fictitious phase. Therefore, one can have

$$
\begin{aligned}
& \mathrm{i}{ }^{*}{ }_{s a}={ }^{*}{ }_{s D p h} \cos \theta_{a}-I^{*}{ }_{s Q p h} \sin \theta_{a} \\
& \mathrm{i}^{*}{ }_{\mathrm{sc}=} \mathrm{I}^{*}{ }_{\mathrm{sDph}} \cos \theta_{\mathrm{c}}-\mathrm{I}^{*}{ }_{\mathrm{sQph}} \sin \theta_{\mathrm{c}}
\end{aligned}
$$

Three-phase reference source currents $\left(i^{*}{ }_{s a}, i^{*}{ }_{s b}\right.$, and $\left.i^{*}{ }_{s c}\right)$ are compared with the sensed source currents $\left(i_{\mathrm{sa}}, i_{\mathrm{sb}}\right.$, and $i_{\text {sc }}$ ) and the current errors are computed as

$$
\mathrm{i}_{\mathrm{aerr}}=\mathrm{i}_{\mathrm{sa}}-\mathrm{i}_{\mathrm{sa}}
$$

$$
\begin{aligned}
& \mathrm{i}_{\text {berr }}=\mathrm{i}^{*}{ }_{\mathrm{sb}}-\mathrm{i}_{\mathrm{sb}} \\
& \mathrm{i}_{\text {cerr }}=\mathrm{i}^{*}{ }_{\mathrm{sc}}-\mathrm{i}_{\mathrm{sc}}
\end{aligned}
$$

These current error signals are fed to the currentcontrolled PWM pulse generator for switching the IGBTs of the STATCOM. Thus, the generated PWM pulses are applied to the STATCOM to achieve sinusoidal and balanced source currents along with desired voltage regulation

\section{FUZZY LOGIC CONTROLLER}

Fuzzy logic is a method of rule-based decision making used for expert systems and process control that emulates the rule-of-thumb thought process used by human beings. The basis of fuzzy logic is fuzzy set theory which was developed by Lotfi Zadeh in the 1960s. Fuzzy set theory differs from traditional Boolean (or two-valued) set theory in that partial membership in a set is allowed. Traditional Boolean set theory is two-valued in the sense that a member belongs to a set or does not and is represented by 1 or 0 , respectively. Fuzzy set theory allows for partial membership, or a degree of membership, which might be any value along the continous of 0 to 1 .

A linguistic term can be defined quantitatively by a type of fuzzy set known as a membership function. The membership function specifically defines degrees of membership based on a property such as temperature or pressure. With membership functions defined for controller or expert system inputs and outputs, the formulation of a rule base of IF-THEN type conditional rules is done. Such a rule base and the corresponding membership functions are employed to analyze controller inputs and determine controller outputs by the process of fuzzy logic inference.

By defining such a fuzzy controller, process control can be implemented quickly and easily. Many such systems are difficult or impossible to model mathematically, which is required for the design of most traditional control algorithms. In addition, many processes that might or might not be modeled mathematically are too complex or nonlinear to be controlled with traditional strategies.

A fuzzy controller converts a linguistic control strategy into an automatic control strategy, and fuzzy rules are constructed by expert experience or knowledge database. Firstly, input voltage $V_{d c}$ and the input reference voltage $V_{d c-r e f}$ have been placed of the angular velocity to be the input variables of the fuzzy logic controller. Then the output variable of the fuzzy logic controller is presented by the control Current Imax. To convert these numerical variables into linguistic variables, the following seven fuzzy levels or sets are chosen as: NB (negative big), NM (negative medium), NS (negative small), ZE (zero), PS (positive small), PM (positive medium), and PB (positive big) as shown in Figure.7.

The fuzzy controller is characterized as follows:

1) Seven fuzzy sets for each input and output;

2) Fuzzification using continuous universe of discourse;

3) Implication using Mamdani's 'min' operator;

4) De-Fuzzification using the 'centroid' method. 
INTERNATIONAL JOURNAL OF INNOVATIVE RESEARCH IN ELECTRICAL, ELECTRONICS, INSTRUMENTATION AND CONTROL ENGINEERING Vol. 3, Issue 12, December 2015

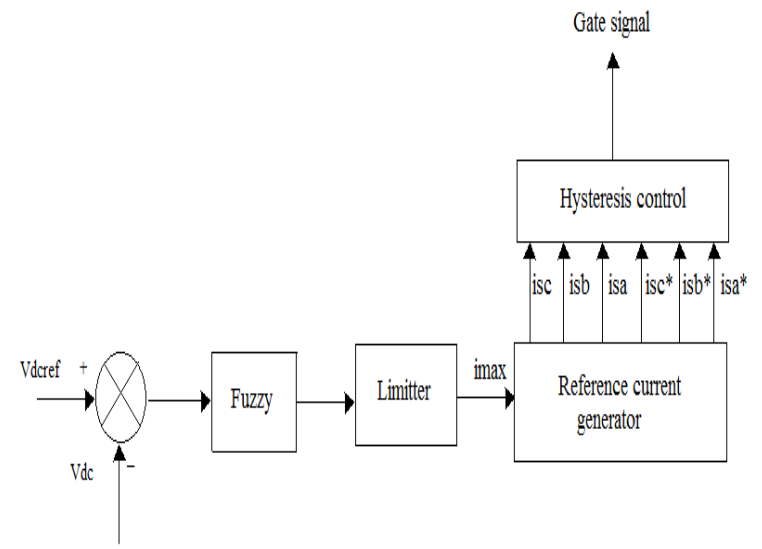

Fig.4. Conventional fuzzy controller

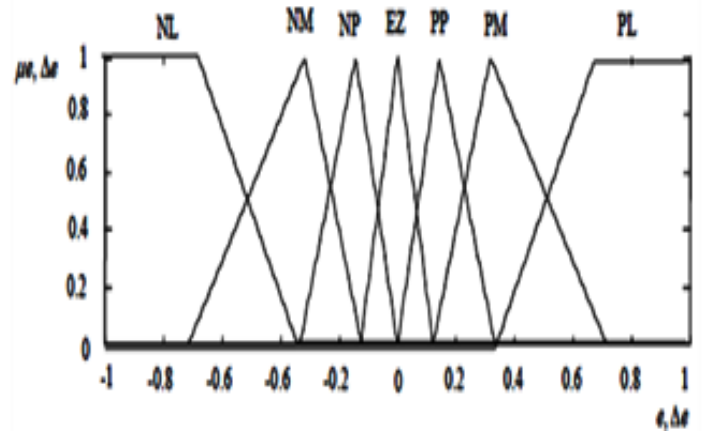

Fig.5.Membership functions for Input, Change in input, Output.

Fuzzification: the process of converting a numerical variable (real number) convert to a linguistic variable (fuzzy number) is called fuzzification.

De-fuzzification: the rules of FLC generate required output in a linguistic variable (Fuzzy Number), according to real world requirements, linguistic variables have to be transformed to crisp output (Real number).

Database: the Database stores the definition of the membership Function required by fuzzifier and defuzzifier.

Rule Base: the elements of this rule base table are determined based on the theory that in the transient state, large errors need coarse control, which requires coarse input/output variables; in the steady state, small errors need fine control, which requires fine input/output variables. Based on this the elements of the rule table are obtained as shown in Table 1 , with ' $V d c$ ' and ' $V_{d c-\text { ref }}$ as inputs. Table I Fuzzy Rules

\begin{tabular}{|c|c|c|c|c|c|c|c|}
\hline & NL & NM & NS & $\mathrm{EZ}$ & PS & $\mathrm{PM}$ & PL \\
\hline NL & NL & NL & NL & NL & $\mathrm{NM}$ & NS & EZ \\
\hline $\mathrm{NM}$ & NL & NL & NL & $\mathrm{NM}$ & NS & EZ & PS \\
\hline NS & NL & NL & NM & NS & $\mathrm{EZ}$ & PS & $\mathrm{PM}$ \\
\hline $\mathrm{EZ}$ & NL & $\mathrm{NM}$ & NS & EZ & PS & $\mathrm{PM}$ & PL \\
\hline PS & $\mathrm{NM}$ & NS & $\mathrm{EZ}$ & PS & PM & PL & PL \\
\hline $\mathrm{PM}$ & NS & $\mathrm{EZ}$ & PS & PM & PL & PL & PL \\
\hline PL & NL & $\mathrm{NM}$ & NS & EZ & PS & $\mathrm{PM}$ & PL \\
\hline
\end{tabular}

TABLE I: Rule Base

\section{MATLAB/SIMULINK RESULTS}

Here the simulation is carried out by four cases and shown in bellow Figs.6 to 20. Case.1.For linear load with rated voltage. Case.2. for Single phase non linear load. Case.3. for Single phase decreasing non linear load Case.4. Single phase non linear load with fuzzy controller.

\section{Case1: Linear Load With Rated Voltage}

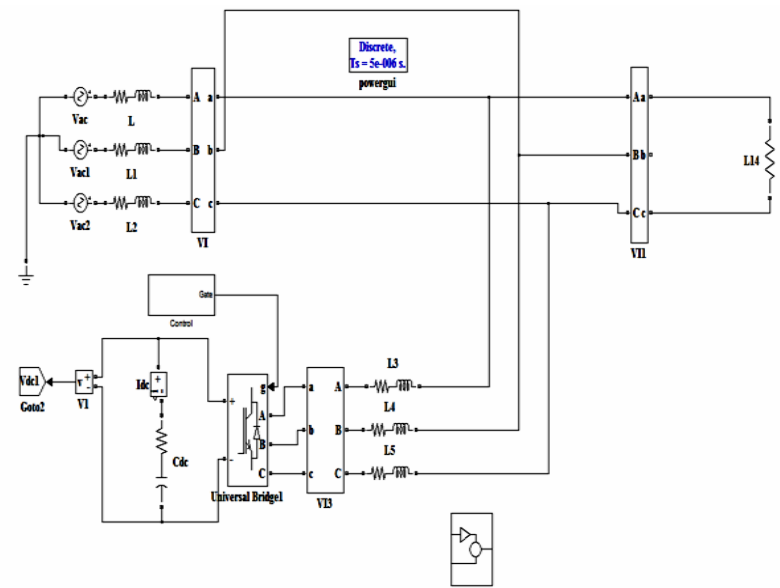

Fig.6.Simulink Circuit for Linear Load with rated voltage

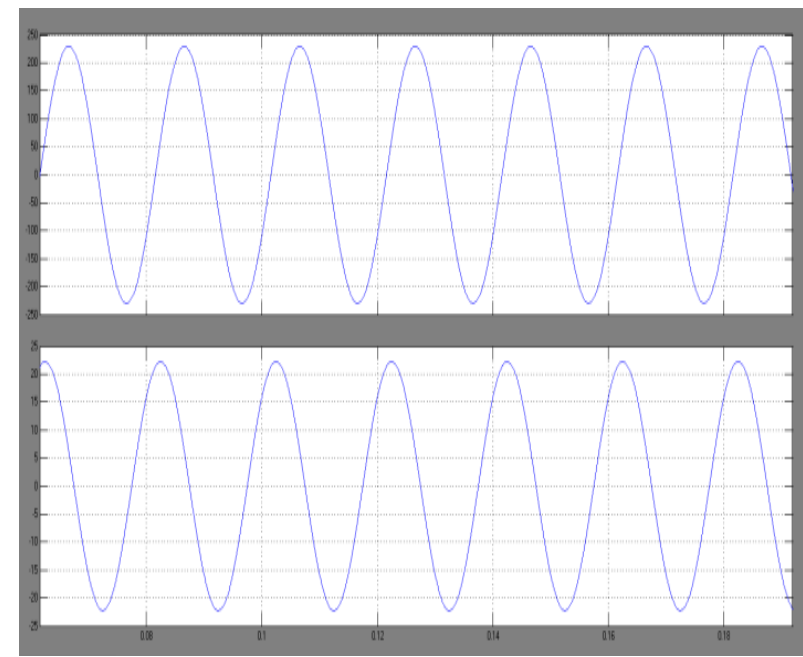

Fig.7.Single Phase Source Voltage and Current at rated Voltage Condition.

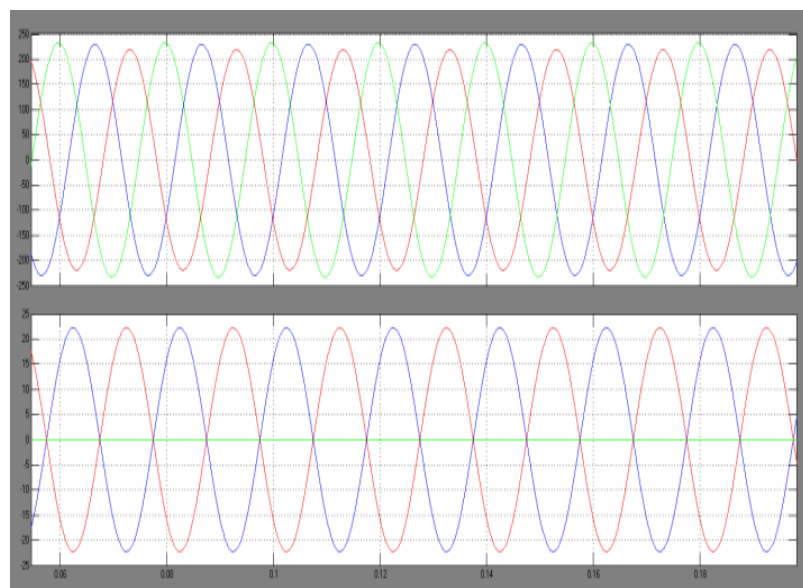

Fig.8.Three Phase Source Voltage and Load Current at rated Voltage Condition. 
Case2: For Single Phase Non Linear Load

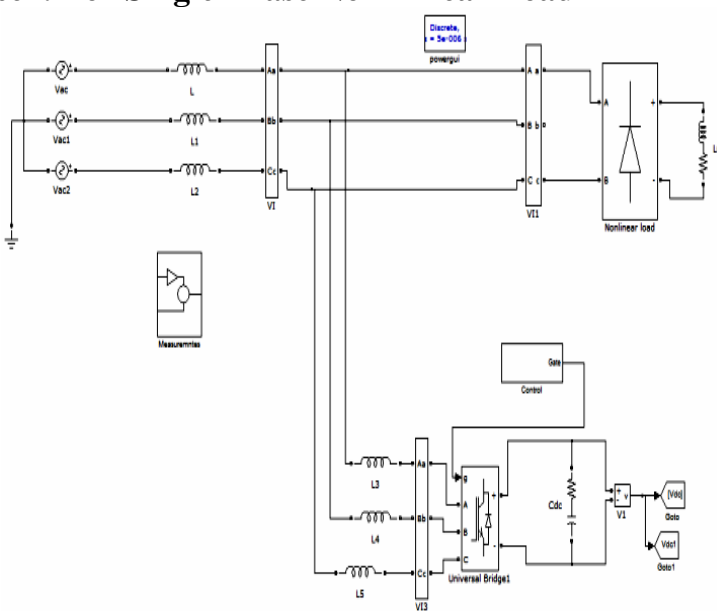

Fig.9.Simulink Circuit for Single Phase Non Linear load.

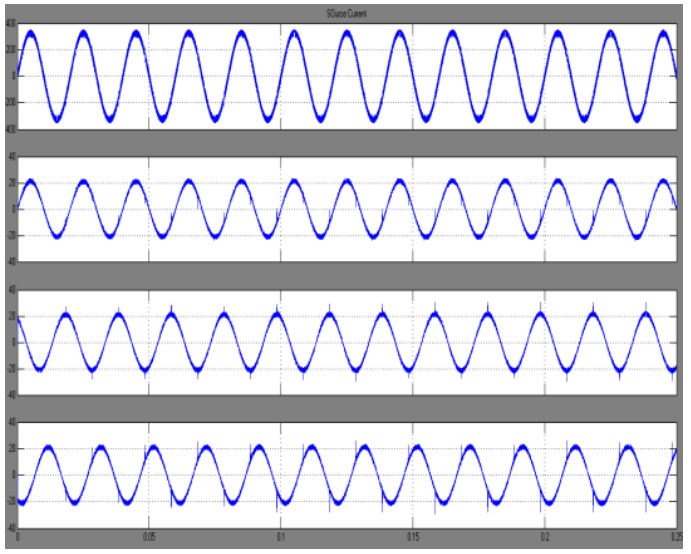

Fig.10.Simulation results for Source Voltage and Source Currents.

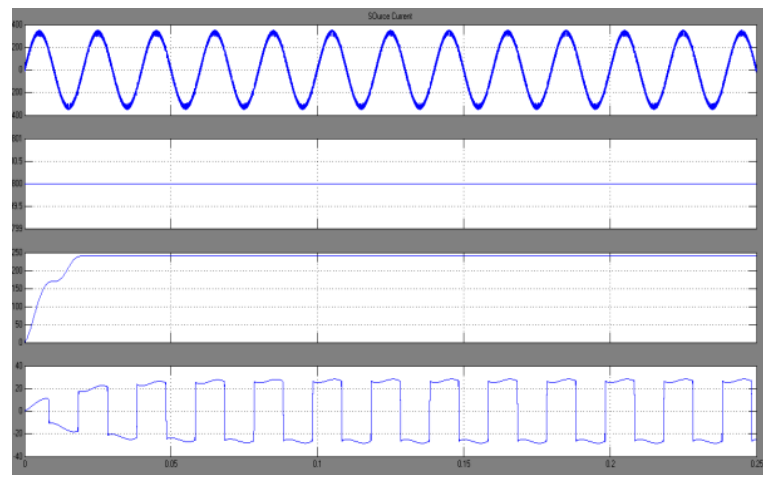

Fig.11.Simulation results for Source Voltage, dc link Voltage, $\mathrm{V}_{\mathrm{t}} \mathrm{rms}$ Voltage and Load Current.

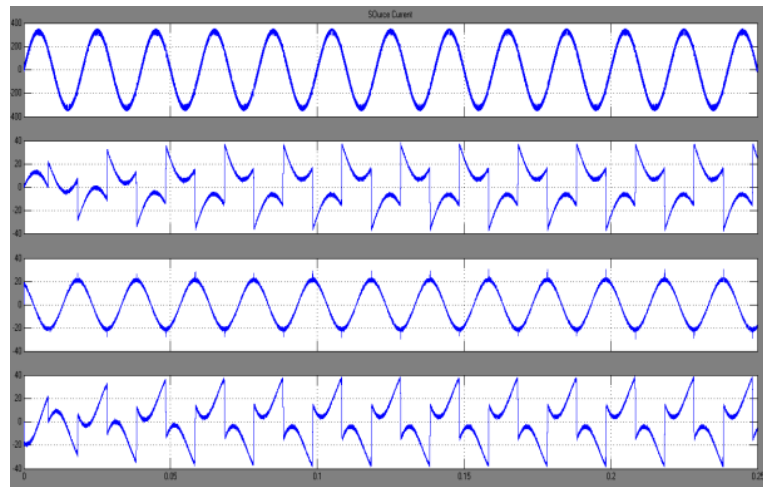

Fig.12.Source Voltage and Compensation Currents.

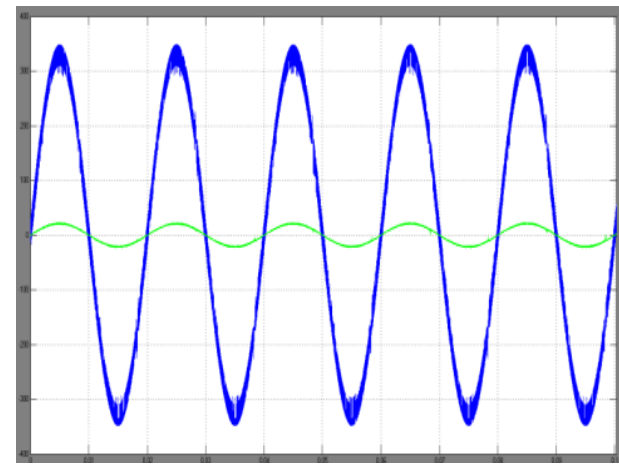

Fig.13.Simulated results for Unity Power factor.
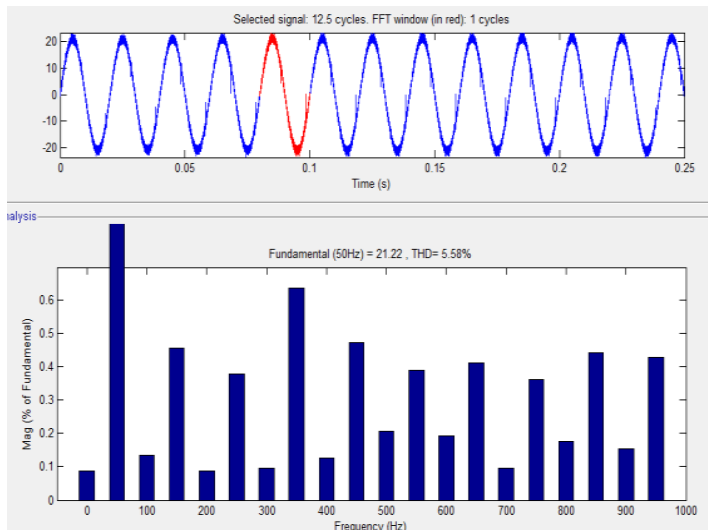

Fig.14.THD analysis for Source Voltage.

Case 3: For Single Phase Decreasing Non Linear Load

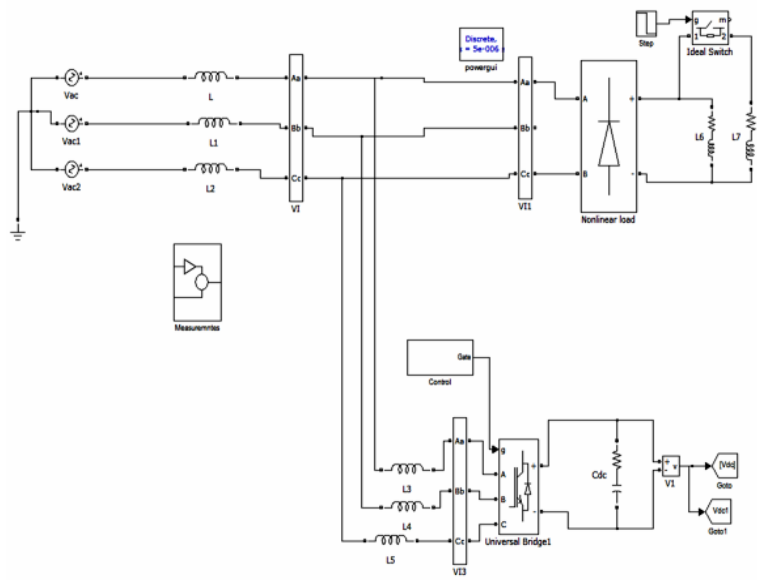

Fig.15.Simulink circuit for single phase decreasing non linear load.

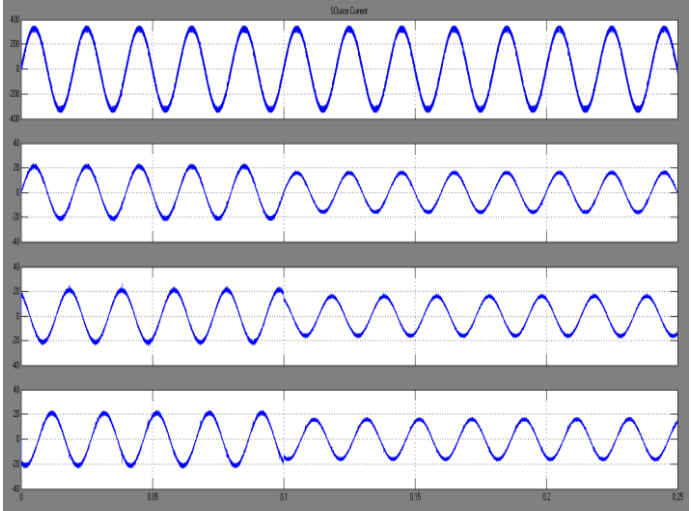

Fig.16.Simulation results for Source Voltage and Source Currents. 


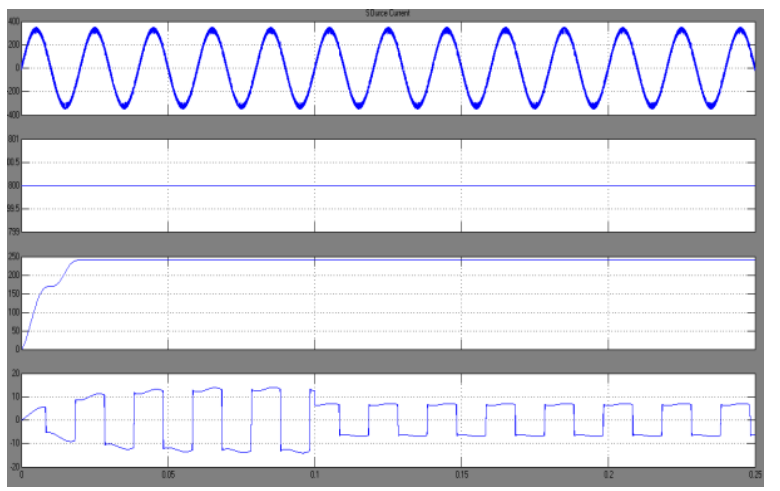

Fig.17.Simulation results for Source Voltage, dc link Voltage, $\mathrm{V}_{\mathrm{t}} \mathrm{rms}$ Voltage and Load Current.

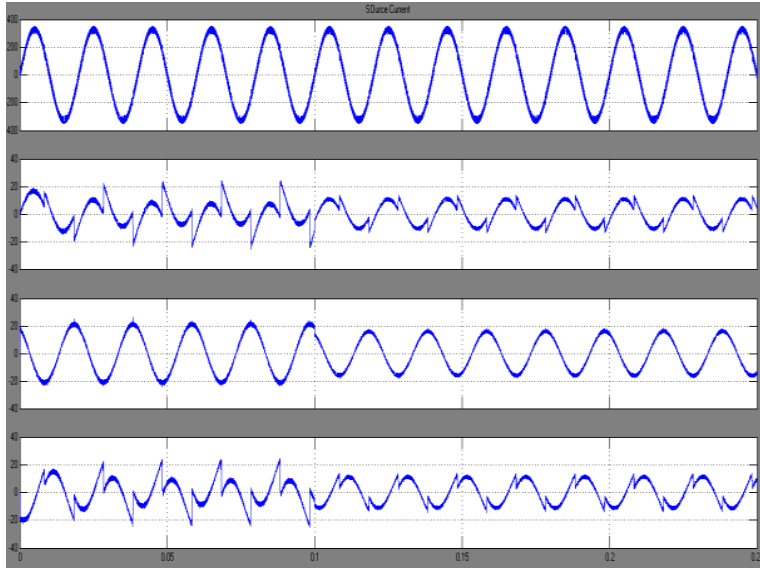

Fig.18.Source Voltage and Compensation Currents.

Case 4: Single Phase Non Linear Load With Fuzzy Controller

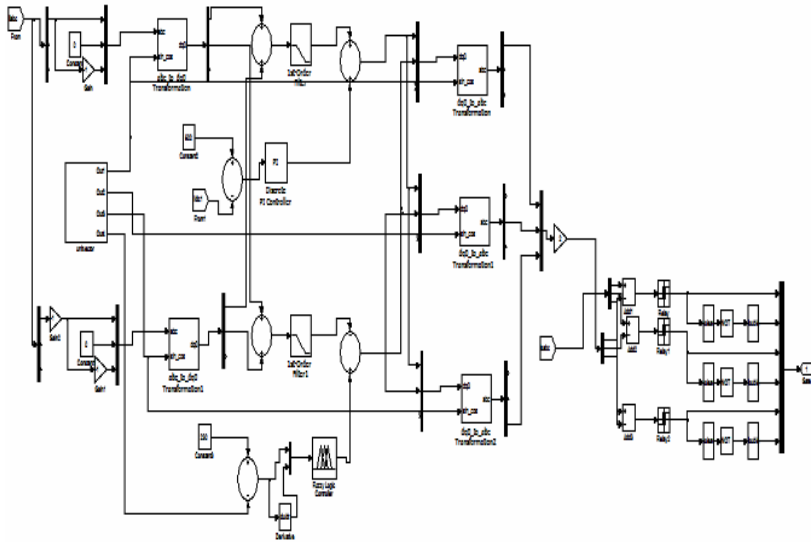

Fig.19.Simulink Circuit by using Fuzzy.

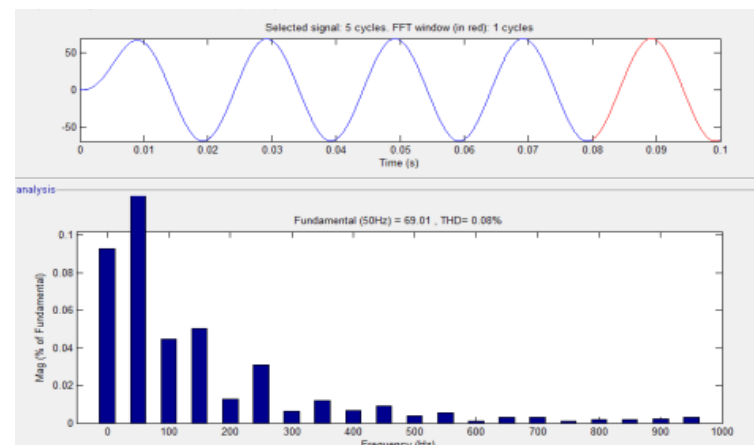

Fig.20.FFT analysis for Source Current by using Fuzzy Controller

\section{CONCLUSION}

The proposed method of feeding single-phase loads from a three-phase SEIG and STATCOM combination has been simulated, and it has been proved that the SEIG is able to feed single phase loads up to its rated capacity. A singlephase synchronous D-Q frame theory-based control of a three-phase STATCOM has been proposed, discussed, and this control technique we compare both PI and Fuzzy controllers. The source current THD by using PI controller is $5.58 \%$ and THD value by using fuzzy controller is $0.08 \%$. So finally we conclude that fuzzy controller is the better control technique instead of PI Control.

\section{REFERENCES}

[1] E.D. Bassett and F.M. Potter, -Capacitive excitation for induction generators,\| Trans. Amer. Inst. Elect. Eng., vol. 54, no. 5, pp. 540-545, May 1935

[2] J.E. Barkle and R.W. Ferguson, -Induction generator theory and application,\| Trans. Amer. Inst. Elect. Eng., vol. 73, no. 1, pp. 12-19, Jan.1954.

[3] (2013).[Online].Available: ttp://www.picohydro.org.uk [4] N. Smith Motors as Generators for Micro-Hydro Power. London, U.K.: ITDG Publishing, 1994.

[5] S. Khennas and A. Barnett, -Best practices for sustainable development of micro hydro power in developing countries, $\|$ World Bank, Washington, DC, USA, ESMAP Tech. Rep. 21640, no. 6, 2000.

[6] H. Rai, A. Tandan, S. Murthy, B. Singh, and B. Singh, -Voltage regulation of self excited induction generator using passive elements, $\|$ in Proc. IEEE Int. Conf. Elect. Mach. Drives, Sep. 1993, pp. 240-245.

[7] L. Shridhar, B. Singh, and C. Jha, - Transient performance of the self regulated short shunt self excited induction generator,„IEEE Trans. Energy Convers., vol. 10, no. 2, pp. 261-267, Jun. 1995.

[8] E. Bim, J. Szajner, and Y. Burian, -Voltage compensation of an induction generator with long-shunt connection,\| IEEE Trans. Energy Convers., vol. 4, no. 3, pp. 526-530, Sep. 1989.

[9] L. Shridhar, B. Singh, C. Jha, B. Singh, and S. Murthy, - Selection of capacitors for the self regulated short shunt self excited induction generator,\| IEEE Trans. Energy Convers., vol. 10, no. 1, pp. 10-17, Mar. 1995

[10] L. Wang and C.-H. Lee, - - Long-shunt and short-shunt connections on dynamic performance of a SEIG feeding an induction motor load, II IEEE Trans. Energy Convers., vol. 15, no. 1, pp. 1-7, Mar. 2000.

[11] M. B. Brennen and A. Abbondanti, -Static exciters for induction generators,\| IEEE Trans. Ind. Appl., vol. IA-13, no. 5, pp. 422-428, Sep. 1977.

[12] B. Singh and L. Shilpakar, - Analysis of a novel solid state voltage regulator for a self-excited induction generator,\| IEE Proc.-Generat. Transmits. Distrib. vol. 145, no. 6, pp. 647-655, Nov. 1998

[13] S.-C. Kuo and L. Wang, - Analysis of voltage control for a self-excited inducNtion generator using a current-controlled voltage source inverter (CC-VSI), IIEE Proc.—Generat. Transmits. Distrib., vol. 148, no. 5, pp. 431-438, Sep. 2001.

[14] B. Singh, S. Murthy, and S. Gupta, -STATCOM-based voltage regulator for self-excited induction generator feeding nonlinear loads, $\|$ IEEE Trans. Ind. Electron., vol. 53, no. 5, pp. 1437-1452, Oct.2006.

[15] G. Dastagir and L. A. C. Lopes, - Voltage and frequency regulation of a stand-alone self-excited induction generator, $\|$ in Proc. IEEE Electr. Power Conf., 2007, pp. 502-506.

\section{BIOGRAPHIES}

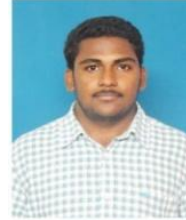

Addanki Gopinadh, M.Tech scholar in Amrita Sai Institute of Science and Technology, Paritala, Krishna. I Secured my B.Tech Degree in the year 2011 from the Institute of St'anns College of Engineering and Technology, Chirala.Prakasam.

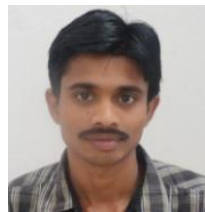

Pasupulety AnkamaRao, working as Assistant. Professor in Amrita Sai Institute of Science and Technology, Paritala, Krishna. $\mathrm{He}$ secured M.tech Sasi Institute of Technology\& Engineering Tadepalligudem, West Godavari. 